\title{
New Kid On The Block! Understanding Blockchain Adoption in the Public Sector
}

\author{
Fay Koster \\ Accenture \\ fhekoster@gmail.com
}

\author{
Hans P. Borgman \\ University of Amsterdam Business School \\ h.p.borgman@uva.nl
}

\begin{abstract}
Blockchain has been heralded as a technology that can transform entire sectors, including the public sector where blockchain applications are believed to bring a wide range of benefits. The public sector is lagging behind, however, in its actual adoption of blockchain technology, and our understanding of the factors that explain the slow adoption rate, is lacking. Based on seven case studies of blockchain projects at various adoption stages, this research contributes to our understanding of what factors influence blockchain adoption in the public sector. We use an extended TOE framework that includes an inter-organizational perspective. The findings show that adoption is influenced by the hype around-and resistance toblockchain technology; by top management support, by (perceptions of) the regulatory environment; as well as by trust between blockchain partners, which is both an antecedent as well as a consequence of blockchain adoption.
\end{abstract}

\section{Introduction}

Blockchain is heralded as a major disruptive technology, with "the capacity for reconfiguring all aspects of society and its operations" [1, p. ix]. In recent years, the technology has evolved beyond initial payment solutions in the financial sector and it is perceived as holding the promise of being transformative for a wide range of sectors, including the public sector [2], [3].

For the public sector, adoption of new technologies to increase effectiveness and efficiency has become critical and blockchain could indeed bring great benefits that match the specific role of many public organizations in society, due to its role as trusted party and the key role security, traceability, transparency, and accountability play in its services and transactions [3]. Benefits include improved data integrity and -quality, avoidance of fraud and manipulation, reduced corruption, and enhanced trust [4]. Furthermore, blockchain is believed to bring valuable opportunities for the improvement of core governmental activities such as digital ID management, secure record-keeping, and document handling. Not the least important, successful applications in the public sector hold the potential of stimulating development of blockchain applications across all industries, as many governments have high trust and a large user base [2].

However, in comparison to other sectors, the public sector is lagging behind when it comes to unlocking blockchain's potential. Since 2017, blockchain experiments in the public sector have accelerated, with many experiments planned or in progress [5], indicating government leaders' awareness of the potential. However, this relatively new 'wave' consists mostly of isolated initiatives, unique to the particular circumstances of the country, municipality, etc., [5]. Many global-scale applications were announced, but so far these remain not fully implemented. Use cases remain visionary ambitions as execution and practical demonstration of the experiments remains incomplete. Moreover, signs indicate that in the public sector, active experimentation - a crucial stage in the adoption process - is currently declining [6], [7].

Apart from the aforementioned market studies, few studies have been published on blockchain adoption in the public sector, and we have limited insight on the drivers and impediments to adoption. For instance, how is the adoption of blockchain applications influenced by the unique role of government as the legislative authority [2]? How do the factors of trust between blockchain partners, and resistance to blockchainimposed changes on the current role of government, influence adoption [8]?

Contributions are made to our understanding of what factors influence blockchain adoption in the public sector, both on a theoretical and empirical level. Findings are academically relevant as light is shed on how the unique role of public organizations influences adoption for example due to their role as trusted third party and governmental organizations' share in the access to- and control over citizen data. Practical value is evident as our study provides knowledge and guidance to public organizations on how the adoption of 
current- as well as future blockchain projects may be influenced and recommendations are made which allow optimization and advanced adoption. This is reflected in the following research question: What factors influence blockchain adoption in the public sector?

This exploratory research is based on seven case studies of blockchain applications that all involve one or more (semi)public organizations. Case studies are a particularly appropriate method when studying a novel phenomenon in its natural context [9]. All cases are set in the Netherlands, both as opportunity sample due to the location of the authors, as well as to have a comparable context in terms of regulatory environment and other factors.

To guide our exploration, we build upon a theoretical firm-level adoption framework that is widely used and has been shown to have good explanatory power in the public sector, also for newer technologies such as cloud computing [10]; Tornatzky and Fleisher's Technology-Organization-Environment

(TOE) framework [11], [12]. Although the TOE framework includes multiple perspectives or 'contexts', blockchain applications have some special characteristics whose impact on adoption cannot easily be captured in either the $\mathrm{T}, \mathrm{O}$ or $\mathrm{E}$ perspective. Specifically, blockchain applications always involve multiple parties in an interorganizational setting [8] [2], and the technology, as its core, has a built-in transaction verification and authentication mechanism that makes it "trust-free" [1]. As argued earlier, the public sector has a unique role as a trusted party, and blockchain's potential to support or challenge that role may very well have an impact on adoption. We therefore extend the TOE framework with an interorganizational perspective that also pays specific attention to trust [13]. This extension allows us to not only provide a more complete understanding of blockchain adoption, but also to increase the explanatory power of the TOE framework, providing actionable, practical insights that are meaningful in the global context of increasing organizational interconnectedness [12].

The remainder of this paper is organized into four sections. In the following section our research propositions that guide the exploration are derived from the extant literature. The research method is further described in section 3. Section 4 describes the cases, and in section 5 the cross case analysis is performed. Section 6 discusses the findings and suggests avenues for future research.

\section{Literature review and propositions}

To contribute to our understanding of blockchain adoption by public organizations, we first discuss the three buildings blocks of the TOE-framework, followed by the interorganizational context. Within each context, we explore factors influencing blockchain adoption. Four propositions are derived that lead the data collection and analysis process.

\subsection{Technological context}

The technological context encompasses all technologies that are relevant to the organization. This includes technologies already in use by the organization as well as innovations accessible in the market, but not yet in use [12]. Blockchain technology is often considered a hype that acquired its attraction as the underlying technology of the cryptocurrency Bitcoin [14], [15]. In this hype, Blockchain (in early 2019 when data were collected) is portrayed as nearing the end of the 'Peak of Inflated Expectations' in Gartner's Hype Cycle for Emerging Technologies [16]. During this peak, "bandwagon effects" or the "fear of missing out" cause organizations to hasten to adopt and the technology is applied in a range of settings, without sufficient attention to organizational readiness, use cases or task-technology fit [17]-[19].

Where Blockchain's hype may push adoption, its "trust-free" features are often perceived as making it potentially disruptive for many types of transactions and processes, particularly in the public sector [15], [3] potentially leading to resistance. Resistance is argued to be one of the major roadblocks for adoption [20], [21]. These opposing forces of the excitement caused by the hype as well as the resistance to adopt the technological innovation is reflected in the following proposition:

Proposition 1: Public sector adoption of blockchain is influenced by the opposing forces of technology hype and resistance.

\subsection{Organizational context}

The organizational context broadly refers to the characteristics and resources of the firm, such as size, linking mechanisms between employees, the amount of slack resources [12], and top management support. Particularly top management support is seen as essential to technology adoption [22], [23]. This support can take many forms, from participation in activities or personal interventions in the management of technology to executive involvement as a psychological state that reflects the degree of importance placed on technology [24], [25]. Within the public sector, top-management not only refers to civil servants, but also to politicians, and this adds an extra layer which emphasizes factors such as a potential lack of continuity, a lower risk appetite or a stronger reaction to hypes [26]. This leads to the following proposition: 
Proposition 2: Top-management support in Blockchain adoption within the public sector is particularly important and dynamic.

\subsection{Environmental context}

The environmental context refers to the area in which the organization conducts its day-to-day business. This includes industry characteristics, the technology support infrastructure, and the regulatory environment [11]. The last entails government regulations which can have a beneficial- or detrimental effect on innovation adoption. Regulations can speed up innovation, for example by making a technological inovation essentially mandatory due to imposing constraints on an industry (such as pollution-control) and similarly innovation in industries can be hampered by constraining laws (such as privacy requirements) [12]. The regulatory environment has been shown to be influential on the adoption of a range of novel technologies [25], [27], including Blockchain [2]-[4], [22]. As discussed in the introduction section, the specific role of public organizations in society has such a close task-technology fit with blockchain, that one can expect an even greater influence of regulation to adoption. This then leads to the proposition:

Proposition 3: The regulatory environment is perceived as a particularly influential challenge to blockchain adoption in the public sector.

\subsection{Interorganizational context and trust}

The interorganizational context is useful for understanding the interorganizational relationships of the organization and the impact thereof on the adoption of a technological innovation [13]. The adoption of blockchain, comparable to the adoption of IOS [13], impacts the cooperation of the organization with other parties [1], and therefore, various aspects of interorganizational relationships are argued to influence its adoption. Chwelos et al. discuss the value of extending the TOE framework with an interorganizational perspective in the case of EDI adoption [28]. Differences between (inter) organizational adoption factors are also found by Henderson et al. who looked at XBRL [29].

Within this context, the factor trust, as a sociopolitical force between parties in a relationship, plays an important role on technology adoption. Trust in a partner improves the relationship among partners and simultaneously works a restraint for opportunistic behaviors. Consequently, trust among partners has a positive influence on technology adoption [30], [31]. The technological innovation of blockchain, however, works as a "trustless" proof mechanism holding all transactions among parties on the network. Parties can trust the system, instead of counterparties or an intermediary [1]. The immutability, and transparency of the blockchain system may enhance, or even create trust among all parties [1], [4]. Furthermore, the technology supports information exchange and transactions that require authentication and trust [8], [32]. These findings are reflected in the following proposition:

Proposition 4: Trust among collaborating parties positively influences blockchain adoption and adoption increases trust among involved parties.

\section{Research method}

The multiple case study strategy serves the aim of this research to find answers to "how", and "why" questions, and to uncover patterns. Seven blockchain projects are studied, set in a comparable context which increases the ability to replicate findings across cases and enhances the reliability, and external validity of our research [9]. The cases were carefully selected, based on their relevance for the public sector, and for their illustration of different blockchain applications, and adoption stages. Sixteen semi-structured interviews form the primary source of evidence, supporting the exploratory nature of this study [33]. The evidence is strengthened with documentation on the blockchain projects obtained from the case organizations themselves or taken from published interviews or documents, as well as observation notes taken during the interview (regarding work atmosphere, side conversations when interviewees were interrupted, etc.). This manner of data triangulation enhances the reliability and validity of our findings [9]. Interviewees had varying backgrounds in the organization and different responsibilities in the project. All interviews were aimed at identifying the interviewee's unique, differing perspectives on adoption, further strengthening the case study [34]. Each interview was conducted at the interviewee's organization, lasted around 60 minutes, and was recorded, transcribed and analyzed. The interview guideline ensured that data was collected on all propositions created in section 2 , but the guideline merely served as a checklist and interviewees were encouraged to expand into other areas as they saw relevant, in line with the exploratory purpose of the study. To further improve construct validity, two interviews were conducted prior to the case studies, with consultants with an expertise in blockchain, and specifically the adoption thereof in the public sector, and based on that, the interview guideline was optimized [9].

To become closely familiar with each case as a stand-alone entity, and to allow for the discovery of their unique patterns, first a within-case analysis is performed. Afterwards, a cross-case analysis allows for 
the comparison of identified patterns. This enables us to capture novel findings, generalize patterns [35] and move towards valid conclusions [33]. For each case the propositions are examined using direct quotations of interviewees, documentation and observation notes, allowing for the development of strong, plausible and fair arguments supported by the collected data [9]. Table 1 illustrates this analysis method.

\section{Table 1. Analysis case 2 proposition 2}

\begin{tabular}{|c|}
\hline $\begin{array}{l}\text { Proposition 2: Top-management support in Blockchain adoption } \\
\text { within the public sector is particularly important and dynamic. }\end{array}$ \\
\hline $\begin{array}{l}\text { Finding 1: The project originated from the organization's } \\
\text { innovation lab, which is fully responsible for it, support in } \\
\text { this phase is in the form of being fully set free to explore and } \\
\text { work on the project. As the project advances and results are } \\
\text { demonstrated, interest- and engagement of higher } \\
\text { management increases. Expectations are that when future } \\
\text { results will become visible, support will further increase. }\end{array}$ \\
\hline $\begin{array}{l}\text { Quote 1: "The idea for Financial Emergency Stop } \\
\text { originated from the innovation lab. It starts with the } \\
\text { support the lab receives from higher management." }\end{array}$ \\
\hline $\begin{array}{l}\text { Quote 2: "meanwhile we could do our work ... that } \\
\text { cumulated in the end ... we had the demonstration where } \\
\text { we showed that it worked, it was possible, it was right, } \\
\text { and then you see interest of higher management } \\
\text { increase" }\end{array}$ \\
\hline $\begin{array}{l}\text { Quote 3: "[future change in support] } 100 \% \text { depends on } \\
\text { the results ... if those are in the interest of higher } \\
\text { management, you get instant support." }\end{array}$ \\
\hline
\end{tabular}

\section{Cases}

Table 2 presents the cases of this study together with descriptive information on each case. Each case involves one or more (semi)public organizations and is at least partially set in The Netherlands which enhances comparability. Expected benefits and use cases of the projects include enhanced citizen control over personal data, enhanced avoidance of fraud and manipulation, enhanced trust, transparency, traceability and supply chain efficiency. All projects in their current form range in duration between 1-2 years, and all -except Blocklab - are in the early phases of the project before going live which further increases comparability of the results. Interviewees employ varying roles ranging from IT architect, Project Sponsor, and Blockchain Program Manager, Coordinator and Advisor to Commercial Stream Lead.

\section{Cross case analysis}

The cross-case analysis includes direct quotations from the interviews, extant literature, project documentation and observation notes, thereby further enhancing the internal validity and generalizability of this research [9]. Table 3 presents an overview of proposition support per case.
Table 2. Case study overview: general information per case

\begin{tabular}{|c|c|c|c|c|}
\hline $\begin{array}{l}\text { Cas } \\
\text { e \# }\end{array}$ & $\begin{array}{l}\text { Project } \\
\text { Name }\end{array}$ & $\begin{array}{l}\text { Short description of } \\
\text { project }\end{array}$ & $\begin{array}{l}\text { Main } \\
\text { organizations } \\
\text { involved }\end{array}$ & $\begin{array}{l}\text { Duratio } \\
\text { n of the } \\
\text { project }\end{array}$ \\
\hline 1 & Deliver & $\begin{array}{l}\text { Creation of a digital } \\
\text { platform for the } \\
\text { coordination- and } \\
\text { sharing of physical, } \\
\text { financial, and } \\
\text { information streams } \\
\text { among parties }\end{array}$ & $\begin{array}{l}\text { Port of Rotterdam, } \\
\text { ABN Amro, } \\
\text { Samsung SDS }\end{array}$ & $\begin{array}{l}2016- \\
\text { now }\end{array}$ \\
\hline 2 & $\begin{array}{l}\text { Financia } \\
1 \\
\text { Emerge } \\
\text { ncy } \\
\text { Stop }\end{array}$ & $\begin{array}{l}\text { Creation of an } \\
\text { ecosystem giving } \\
\text { citizens control over } \\
\text { their personal, } \\
\text { confidential debt data } \\
\text { and the option to share } \\
\text { this with trusted } \\
\text { organizations }\end{array}$ & $\begin{array}{l}\text { CJIB, Ledger } \\
\text { Leopard, TU Delft }\end{array}$ & $\begin{array}{l}2017- \\
\text { now }\end{array}$ \\
\hline 3 & $\begin{array}{l}\text { Accom } \\
\text { modatio } \\
\mathrm{n} \text { Tax }\end{array}$ & $\begin{array}{l}\text { Automation, and } \\
\text { optimization of the } \\
\text { process of collecting } \\
\text { tourist } \\
\text { accommodation taxes } \\
\text { using a blockchain } \\
\text { solution. }\end{array}$ & $\begin{array}{l}\text { City of Rotterdam, } \\
\text { ICTU, Hogeschool } \\
\text { Rotterdam }\end{array}$ & $\begin{array}{l}2018- \\
\text { now }\end{array}$ \\
\hline 4 & $\begin{array}{l}\text { Sales } \\
\text { tax }\end{array}$ & $\begin{array}{l}\text { Exploration of the } \\
\text { opportunities of } \\
\text { blockchain, the impact } \\
\text { thereof and the } \\
\text { potential products for } \\
\text { sales tax processes }\end{array}$ & $\begin{array}{l}\text { Belastingdienst, } \\
\text { Electronic } \\
\text { Commerce } \\
\text { Platform, Dutch } \\
\text { Blockchain } \\
\text { Coalition } \\
\end{array}$ & $\begin{array}{l}2017- \\
\text { now }\end{array}$ \\
\hline 5 & $\begin{array}{l}\text { Use } \\
\text { Case } \\
\text { Diplom } \\
\text { as }\end{array}$ & $\begin{array}{l}\text { Creation of a network } \\
\text { of trust on European } \\
\text { level for the exchange } \\
\text { of credentials among } \\
\text { member states. }\end{array}$ & $\begin{array}{l}\text { DUO, Flanders, } \\
\text { Wallonia, Norway, } \\
\text { Malta, Spain, } \\
\text { Greece, England }\end{array}$ & $\begin{array}{l}2018- \\
\text { now }\end{array}$ \\
\hline 6 & $\begin{array}{l}\text { Traveler } \\
\text { Digital } \\
\text { ID }\end{array}$ & $\begin{array}{l}\text { Creation of a digital } \\
\text { traveler ID that gives } \\
\text { travelers control over } \\
\text { their data and } \\
\text { organizations } \\
\text { authorized access to } \\
\text { required data. }\end{array}$ & $\begin{array}{l}\text { KLM, Schiphol, } \\
\text { Koninklijke } \\
\text { Marechaussee, } \\
\text { Ministerie van } \\
\text { Binnenlandse } \\
\text { Zaken en } \\
\text { Koninkrijksrelaties } \\
\text {, Idemia, TU Delft } \\
\end{array}$ & $\begin{array}{l}2018- \\
\text { now }\end{array}$ \\
\hline 7 & $\begin{array}{l}\text { Blockla } \\
\text { b }\end{array}$ & $\begin{array}{l}\text { Creation of an } \\
\text { environment where } \\
\text { blockchain use cases } \\
\text { are developed with } \\
\text { alliances of engineers, } \\
\text { developers, system } \\
\text { players and end users }\end{array}$ & $\begin{array}{l}\text { Municipality of } \\
\text { Rotterdam, Port of } \\
\text { Rotterdam, } \\
\text { Innovation Quarter }\end{array}$ & $\begin{array}{l}2017- \\
\text { now }\end{array}$ \\
\hline
\end{tabular}

Table 3. Support of propositions per case

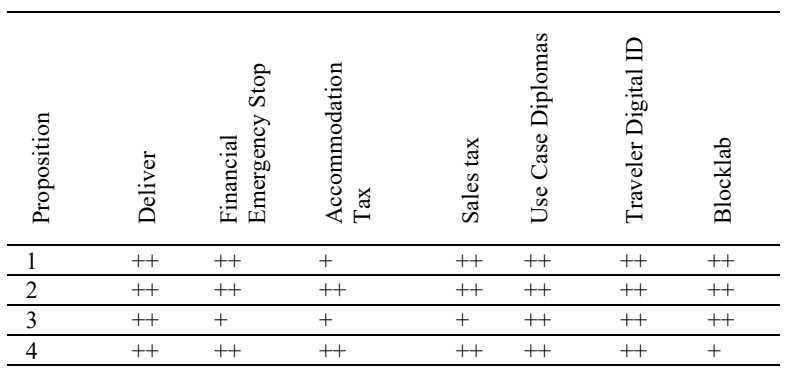

Note: $++=$ Strong support. $+=$ Mild support. $-=$ No support. 


\subsection{P1: Hype vs resistance}

Undeniably, the adoption of blockchain projects is to a greater or lesser extent positively influenced by the effects of the hype surrounding the technological innovation. The manners in- and extent to- which projects have reaped the benefits of the hype vary, and additionally, a relation of the perceived influence of positive effects to time may be observed. All projects were initiated around 1,5 to 2 years ago, with the longest running project, 'Deliver' (case 1), continuing in its current form since 2 years, and the positive influence of the hype is primarily felt in the initial phase of adoption. This is in line with Gartner's Hype Cycle that portrays blockchain at the start of the Peak of Inflated Expectations in July 2016, and nearing the end of the Peak in July 2018 [16], [36]. The positive effects on adoption of a technological innovation being portrayed at the Peak of Inflated Expectations are illustrated by the following examples:

Case 1 has clearly benefitted from the hype as internally, as well as externally, it was helpful for getting support for the project, and as part of the hype a great amount of resources came available to explain what it entailed. The commercial stream lead describes: "you're an early adopter, especially with such a use case, and that creates interest and opens many doors". Similarly, the delegated client of Financial Emergency Stop (case 2) indicates "initially the hype had a positive effect, because the eagerness to learn more about it was big, as well as the readiness ... when I related it to blockchain financial resources became available". Alternatively, the project can even be started in response to high demand from the market to collaborate on blockchain, combined with internal enthusiasm for the topic caused by the hype. This is exemplified by Sales Tax (case 4), where the manager of execution describes: "When we started everyone said: 'this is it, we have to do something with this"'.

However, our findings underscore as well a clear negative influence experienced as consequence of the hype, in large part again related to time. As the projects develop, the hype is perceived to settle, and people become less interested, and voice more criticism, and skepticism arises. Different negative aspects are highlighted by projects, exemplified by the following cases:

The hype forms more of a barrier than a help overall, the IT architect of case 1 states. This is attributed in large part to people's confusion of blockchain with Bitcoin and cryptocurrencies, and the crash thereof: 'That was of course a huge hype", the commercial stream lead explains, 'and then it crashed. Now we are applying it in business while people often cannot even distinguish between crypto and blockchain technology". Likewise, the negative influence of cryptocurrency-confusion is felt by case 2 . Where furthermore a strong influence of skepticism is felt caused by the hype. The project client highlights that "in the end, the hype settled a little, and people became negative: 'blockchain is nothing, will be nothing, an empty bubble"". Again, the influence of time presents itself in case 4 where this is described as "the after hype": long timelines and the changing public opinion make that the attention and support for a project, 'the momentum', disappears. The strategic advisor elaborates: "And then you have the chance that here is no next phase", as 'the investments in time and attention, became more careful".

However, the flip-side becomes visible as the same features of blockchain that caused the hype and excitement, unambiguously inflict resistance to the technological innovation. The influence of resistance on blockchain adoption is evident as all cases indicate experiences with resistance, hampering the project in different forms and levels of intensity. The cases illustrate how projects are influenced by the resistance in response to the unique changes, or the mere threat thereof, that blockchain imposes on an organization. These changes, and perspectives on consequential resistance include the following:

Highlighted by case 1 is that current complexity within organizations fosters jobs, and if that is simplified and automated by blockchain, jobs are affected, inevitably leading to resistance. In the same notion, a developed prototype including automated processes leads to lessened enthusiasm for-, and disassociation of employees with the project as explained by the process manager of Accommodation Tax (case 3), and furthermore, the insecurity felt in the organization is exemplified in case 4 by the following quote: 'help, is our process disappearing?'. This is strengthened by the perception that blockchain requires an organization to drastically change its mindset, and people appear simply unwilling or unable to think radically differently about current issues, as noticed in case 2 and 3. Specifically for IT staff, blockchain implies radical changes in their way of working, stressed in case 2: "with blockchain it's as if you need to drive on the left while we always drove on the right as IT". This brings direct resistance, lack of support and skepticism.

Particular to governmental organizations is their important share in the access to- and control over citizen data. Expected resistance in this regard is highlighted by case 1 , and in case 2 this issue is raised together with the need to reorganize as a government. The latter project holds the belief that data ownership should rest with the citizen, but as the client of the project voices that doesn't mean this belief is widely shared: "if you're convinced that we are the government and we are part of the data 
and owner of that and we decide over you, that's a whole different perspective, and then there's a technique that flips everything around, that's pretty scary', Skepticism is felt. The initiator and sponsor of case 1 continues on the eliminated need for the trusted third party due to blockchain and his expectation of the disturbance this will cause in the public sector. Exemplifying this is the described situation in Use Case Diplomas (case 5). A potential blockchain based solution was presented to the direction of the organization, showing a process lacking the organization itself, and this was indeed met with unease and discussion. The enterprise architect speaks on how blockchain teaches you to think about the potential reorganization of governmental tasks and how it forces you to think about what your role will be then.

\subsection{P2: Top management support}

Our findings show that blockchain adoption is influenced by top management support as they adjust the content as well as the level of their support throughout adoption of the project. The manners in which this occurs, are exemplified by the following cases:

Cases 1, 2, and 5 illustrate how blockchain projects may emerge from bottom-up initiatives and specially designed "labs" within-, or external to the organization. The IT architect of case 1 describes how the project originated from a research project with the university and during the process they were able to create the blockchain field lab to support it. In each of the three cases the lab is set free to experiment on the project, and its employees are fully responsible for its development. At this stage the support of higher management for the project plays a role as this fluctuates from "'willingness: 'you go investigate, try it out'", as described in case 2, to top management initiation of the blockchain lab in case 1 , of which ' 'he is a big sponsor'. Cases 3, 4, and 6 (Traveler Digital ID) present an interesting, alternative route for adoption as these projects originated top-down. The concept of case 6 was originally introduced by the World Economic Forum, and picked up by the Dutch government [37], where ' the importance thereof in the managerial layers was very clear', the project coordinator shares. To test the suitability for further adoption and growth of the concept, a secure lab environment is perceived suitable to first test the Proof of Concept (PoC), and based on the results thereof the decision is made to support the next step of a live pilot [6], [38]. Alternatively, the project may originate from within the organization with ''a strategic question expressed by top management' in case 4, or as in case 3 where ' this director said: I want to do something with this [blockchain], and I think accommodation tax would be a good one to pick up',
All cases indicate how the support of top management fluctuates throughout the various adoption stages based on the outcome of tangible results. Blockchain projects are unique as they offer the organization's employees the opportunity of sharing tangible, interim progress, as seen for example in case 3 where the lead architect describes their creation of 'a working PoC", and "'from that moment that the results were shown to higher management, they became enthusiastic', This observation of increased support throughout duration of the project is made throughout the cases. The IT/innovation manager of case 2 shares: "we had the demonstration where we showed it worked, it was possible, it was right, and then you see interest of higher management increase', , and in case 5 it is illustrated how with the innovation lab a prototype was developed which was later brought back to the director leading to enthusiasm and the response that the project should be taken to the next level, taken to Europe, and in case 1 ''the project started modest, 'you know what, let's do a pilot, a very light MOU', ' 'meanwhile c-level met', who discussed: "'there's potential, we received stuff... let's take the next step" ', Future support and the influence thereof is perceived as uncertain. The level of support "'can go every direction"' (case 1). This again depends on achieved results, "if those are in the interest of higher management, you get instant support' (case 2 ), and "results are your ticket to success"' (case 1), but as well on factors external to the project's influence. Most importantly this depends 'as well on the technological developments', as described by the commercial stream lead of case 1 , and on the success of collaborating with desired partners as "people see the benefit, it just means changing a lot of processes"'.

\subsection{P3: (Perceptions of) the regulatory environment}

This section shows how blockchain projects perceive the regulatory environment as influential and challenging, and how, interestingly, the actual influence thereof on blockchain adoption strongly differs per case as the types of applications, the anticipation on its influence, and adoption stages vary.

Forming a returning topic is the influence of privacy regulations, and more specifically GDPR which came into force last year. There is great unclarity experienced surrounding the influence thereof on the opportunities of blockchain and this challenges adoption. Case 6 clearly describes this: "'worldwide, or on the European level, there is still no clarity', ' 'can you tell me exactly when I can and cannot use it based on GDPR?', The initial promises of blockchain were ' it's disruptive, and everyone has the same copies, well if you want to make that come true you are immediately challenged by those 
privacy rules". The process manager of case 3 explains that the influence of laws and regulations on the project:

' 'is big, privacy and security questions constantly play a role". As projects cross national boundaries, the regulatory environment becomes increasingly complex. The initiator and sponsor of case 1 points out that 'the difficulty is that trade is a worldwide process", so different laws and regulations apply, and 'that makes it complex"'. Or as illustrated by case 5 where it is emphasized that on a European level there is still a lot of synchronization needed among regulations to enable the exchange of diplomas, and that is why the use case is so very complex to make possible.

The influence of laws and regulations is perceived as 'the biggest hindrance I think now for the full automation of supply chains and I think in everything", as described by the IT architect of case 1, and a big role herein is that "'there is nothing or almost nothing put down in law", "so that makes it difficult, because no one knows exactly what they're doing', the commercial stream lead shares. This lagging behind of legal developments on blockchain developments hampers adoption, and it is brought to light throughout projects. ''legal, privacy, that's still a quest and in the end somewhere judges will determine, if we're using this, where the margins are" (case 6). The project coordinator continues to illustrate how blockchain developments may impose challenges on the role of governmental institutions: ' previously we could create a law and say: 'yeah we can, if it doesn't work, change the law,' but if you in code rules put down the law and you want to change it, ... it becomes difficult again'. Similarly, in case 5 the enterprise architect shares his perspective of how the current regulatory environment especially with diplomas in big part might form a barrier for doing things differently. He explains how duties that they have as DUO, like keeping the diploma register, are set by law, so first thing that needs be done before you can start with these types of 'odd' technologies, is change laws and regulations. Especially because blockchain changes a lot and in the end it aims to arrange laws and regulations in a whole different way.

Although the regulatory environment is thus generally perceived as influential, and challenging, our findings underscore as well that time is devoted by projects to anticipate on-, and work with laws and regulations so to mitigate the effects. The legal perspective on the project is often involved early on, so they have time to think about the implications. For case 1 this resulted in a dedicated 'track' within the consortium where legal aspects are investigated. Close collaboration with legal experts enables projects to eliminate worries that were held up-front and perceive laws and regulations as "non-hindering", at their stage of adoption. In cases 3 and 4, the aim was set upfront to find a project that could be done within the current regulatory framework. The lead architect of case 3 explains that the influence was limited: ' the use-case is not that much subject to laws and regulations or at least not those that are very hard to change for the client [city of Rotterdam]', For case 2 close collaboration with an external law firm resulted in making the project "'legally waterproof, and GDPR-proof', in turn allowing advanced adoption. Privacy regulations in this case might be perceived as even driving the blockchain solution, since the aim of the project is to protect the privacy of citizen data. This opportunity for blockchain is emphasized as well in case 7 (Blocklab): ' 'blockchain could be a solution, because you subtract the privacy sensitivity',

\subsection{P4: Trust}

This section highlights the evident importance of the trust factor on blockchain adoption. For adoption of the blockchain project, closely collaborating parties depend on each other, and some level of trust is a prerequisite for engaging in this. In case 1 the IT architect of the project expresses clearly that the influence of trust on the project "'is very high, the good thing is all three parties realize they cannot do this alone ... in the collaboration is where the added value lies, and you can only collaborate if you trust each other''. This is in line with Ølnes \& Jansen's conclusion that to realize the greatest benefit of blockchain, inter-organizational, and potentially international, applications must be build [2]. As the adoption advances, trust further increases. This is partly caused by the collaboration itself: shared learning- and achievement of interim results, parties' intrinsic motivation, and shared focus on- and commitment to achieve the mutual goal. Fascinating is that trust among parties grows as well if there was lack of a basis for this, exemplified by the following quote of case 1: "'in the logistic sector, mutual trust is pretty fragile, many parties collaborate a lot, but that doesn't mean per definition that they trust each other', the initiator and sponsor continues: "what you see in these blockchain processes that by simply collaborating, trust builds. Together you focus on mutual goals", and: ' the more you collaborate, the more trust you build, sounds logic, but that's an important aspect that now lacks'". Alike, in case 2, the IT/innovation manager describes how the complexity of blockchain can form a challenge for trust in the beginning: "'trust needed to grow, it started a little rough ... the whole technical, mathematical, cryptography, those things, I am not a mathematician', ''how do I trust that then, what you're saying?'. Trust again develops: 'they present themselves in a good knowledge-bringing manner, our 
invitations and questions were answered well, and then trust grows', resulting in ''a growth curve of trust',

Shifting our lens slightly, it becomes clear that trust not only positively influences the adoption of the project and is increased due to collaboration, but trust is also positively affected among parties involved in the wider ecosystem of the blockchain application. The influence of blockchain on trust differs per project, and a range of experiences provide an interesting overview of the influence of the technology on the public sector. In the international exchange of diploma certificates, case 5, it is emphasized that trust is of the essential, so you should create a network of trust and blockchain is perceived as an enabler for that. The project exemplifies the expected interesting potential of blockchain for the authentication of documents [2]. In case 4 the manager of execution shares: 'When people want to commit fraud, they can commit fraud, blockchain isn't going to solve that for us', however there is strong believe in blockchain '"as a tool making it easier for people, that they're more inclined to do it well',. When the tax return is created with the use of blockchain "'the odds that it contains errors are simply less high", and as such 'it gives more trust'. Blockchain is thus not perceived as enabling full avoidance of fraud, but nonetheless it proves useful for creating improved trust. Case 2 ''is about that citizens themselves have control over their own personal, trusted data', and the solution makes that the organization can act completely different in the process involving the citizen as opposed to current ways of working, and ' that should solve trust', Similarly, in case 6 the citizen gains more control over their data, nicely described by the following quote: "you return something to me in my digital piece self-sovereign identity", Blockchain is seen as a piece in the total process and it "'makes precisely that that piece of trust can be improved". Cases 2 and 6 thus illustrate the expected suitability of blockchain for digital ID management as a core governmental activity [2]. Lastly, a remarkable difference is seen in blockchain projects, where in case 1 "'the port is seen as a trusted third party", and this role "'as neutral party"' is highly important for 'the power of the collaboration", and in case 3 an interesting different perspective on the role of government presents itself. Here the process manager explains: "we as government, we're also just a trusted third party ... but some things we as government now find that it might be a lot more useful if you [external parties] arrange that amongst yourselves and luckily, we now have a technology that makes that easily possible ... trust is then no longer an issue',

\section{Discussion and suggestions for future research}

The findings of our research support that the adoption of blockchain is influenced by the opposing forces of the hype around-, and resistance to- blockchain technology, top management adjustment of the content and level of their support throughout the project, that the regulatory environment is perceived as influential and challenging, and that trust among parties positively influences adoption, and adoption vice versa positively influences trust. These insights respond to Ølnes \& Jansen's suggestion for further research into the influential factors on the adoption of blockchain in the public sector [2], and it addresses the research question: What factors influence blockchain adoption in the public sector?

Although our findings provide only limited support for proposition 3 regarding the regulatory environment, all projects clearly indicate the significant influence of laws and regulations, and the challenges it may bring, offering valuable insights and strong indirect support. Proposition 1, 2, and 4 receive strong direct support across cases. The projects provide evidence of patterns of similarities as well as valuable differences, and nuances. These explorations, together with the discussed literature, provide a valuable basis for discussing the implications of the propositions, and for suggesting further exploration and testing of the propositions.

A first implication is that the adoption of blockchain projects is influenced by the hype around the technological innovation. Valuable insights are provided on how the hype has an initially more positive and subsequently more negative influence on adoption throughout various adoption stages. This is useful for organizations to be aware of in their adoption of blockchain as well as when considering other technological innovations. As articulated by Deliver's initiator and sponsor: 'it's positive as well as negative so you have to make sure that you use it to your advantage'". Furthermore, valuable insights are provided on how blockchain adoption may lead to resistance in the public sector as it imposes changes on governmental organizations' share in citizen data and as trusted third party. This detailed knowledge is vital since blockchain will only be adopted if resistance can be overcome [14]. Organizations are advised to be mindful of resistance in current- and future adoption stages, and show the added value of the solution, using the words of the manager of execution of Sales Tax: "people only believe it if they see that something actually improves",

A second implication is that top management support is an important factor to consider as influential on blockchain adoption, and the opportunity is big for 
employees to influence the content and level thereof by leveraging the opportunity blockchain projects offer for sharing tangible, interim results. Furthermore, organizations should be aware of the opportunities of supporting new, or existing "labs" to explore blockchain adoption. This is in line with Beck \& MüllerBloch's discussion of an innovation laboratory as organizational enabler for the blockchain innovation process [14]. Future support highly depends on results of projects, the technological developments surrounding blockchain, and the availability of fitting partners.

Another implication rests in our finding of the high influence of privacy, security, and specifically the right to be forgotten. This confirms Ølnes \& Jansen's [8] estimation of these, relatively new, legal barriers. On the other hand, privacy regulations might drive blockchain adoption in the public sector, as illustrated by cases 2 and 7, as it may aid in the protection of the privacy of citizen data. This exemplifies Ølnes \& Jansen's estimation of this enabling side of the same factor [2]. Interestingly, the role of government as legislative authority may enable or controversially hinder adoption as exemplified by case 3 and 6. Moreover, close engagement with legal experts in an early stage of adoption is recommended, so to mitigate the effects of laws and regulations, and further advance adoption.

Our findings provide valuable new insights on the positive role of trust among collaborating partners in the public sector for blockchain adoption, as antecedent as well as consequence of adoption. More trust fosters adoption, and adoption fosters trust, both between the transaction partners as well as in the wider ecosystem of the blockchain application. Cases 5, 4, 2 and 6 illustrate how this is especially relevant for public organizations as these might be involved in "'high-trust" tasks such as the handling of citizen documents, tax administration, and the control of citizen data. The differing experiences on the role of the government as a trusted third party of cases 1 and 3 provide valuable, nuancing insights. On the one hand this responds to Ølnes et al.'s discussion of how blockchain might disintermediate this role by storing official records and offering the data, responding to the necessity of research on this changing role of the government [8]. On the other hand the image of (semi)public organizations as a "trusted third-" or "neutral'" party may be leveraged to enhance the power of the collaboration. It is thereby recommended for future adopters of blockchain in the public sector to dedicate adequate time and resources to developing relationships with collaborating parties and leverage this image.

As a next step it would be interesting to extend this research with longitudinal studies to further improve our understanding of the changes of perceptions, as well as quantifying the results for example through investigation of a larger group of projects and the share of labs therein, combined with perceived support therefor. As the influence of the regulatory environment was indicated as substantial and lacking in clarity by all projects it would be interesting to deeper explore the influence of privacy regulations such as GDPR on blockchain adoption. Furthermore, it is expected that the identified role of trust between blockchain partners, apart from- as well as in combination with the changing role of government, provides fruitful avenues for further exploration.

\section{References}

[1] M. Swan, Blockchain: Blueprint for a new economy. Sebastopol, CA: O’Reilly Media, Inc., 2015.

[2] S. Ølnes and A. Jansen, "Blockchain Technology as Infrastructure - an Analytical Framework," in Proceedings of 19th Annual International Conference on Digital Government Research, 2018.

[3] M. Hancock and E. Vaizy, "Distributed ledger technology: beyond blockchain," 2016.

[4] F. Rizal Batubara, J. Ubacht, and M. Janssen, "Challenges of Blockchain Technology Adoption for eGovernment: A Systematic Literature Review," in Proceedings of 19th Annual International Conference on Digital Government Research, 2018, p. 9.

[5] B. White, M., Killmeyer, J., \& Chew, "Will blockchain transform the public sector? Blockchain basics for government," 2017.

[6] R. Holgate, D. Furlonger, and R. Howard, "Evaluate Promising and Maturing Blockchain Use Cases in Government," 2019.

[7] E. M. Rogers, The Diffusion of Innovations, 3rd ed. New York, NY: Free Press, 1983.

[8] S. Ølnes, J. Ubacht, and M. Janssen, "Blockchain in government: Benefits and implications of distributed ledger technology for information sharing," Gov. Inf. Q., vol. 34, no. 3, pp. 355-364, 2017.

[9] R. K. Yin, Case Study Research and Applications: Design and Methods, 6e ed. Thousand Oaks, CA: Sage Publications, 2018.

[10] A. Polyviou and N. Pouloudi, "Understanding Cloud Adoption Decisions in the Public Sector," in 48th Hawaii International Conference on System Sciences, 2015, pp. 20852094.

[11] L. G. Tornatzky and M. Fleischer, The Process of Technology Innovation. Lexington, MA: Lexington Books, 1990.

[12] J. Baker, "The technology-organization-environment 
framework," in Information systems theory, vol. 1, New York, NY: Springer, 2012, pp. 231-245.

[13] G. Premkumar and K. Ramamurthy, "The Role of Interorganizational and Organizational Factors on the Decision Mode for Adoption of Interorganizational Systems," Decis. Sci., vol. 26, no. 3, pp. 303-336, 1995.

[14] R. Beck and C. Müller-Bloch, "Blockchain as Radical Innovation: A Framework for Engaging with Distributed Ledgers as Incumbent Organization," Proc. 50th Hawaii Int. Conf. Syst. Sci., pp. 5390-5399, 2017.

[15] M. Risius and K. Spohrer, "A Blockchain Research Framework,” Bus. Inf. Syst. Eng., vol. 59, no. 6, pp. 385-409, 2017.

[16] K. Panetta, "5 Trends Emerge in the Gartner Hype Cycle for Emerging Technologies, 2018.," 2018. .

[17] J. Fenn, M. Raskino, and B. Burton, "Understanding Gartner's Hype Cycles," 2018.

[18] A. Leow, A. Litan, R. Hunter, R. Kandaswamy, D. Aron, and A. Stevens, "Predicts 2019 : Blockchain Business," 2018.

[19] H. M. Järvenpää and S. J. Mäkinen, “An empirical study of the existence of the hype cycle: A case of DVD technology," in IEEE Int. Eng. Manage. Conf., 2008, pp. 1-5.

[20] H. Gangwar, H. Date, and R. Ramaswamy, "Understanding determinants of cloud computing adoption using an integrated TAM-TOE model," J. Enterp. Inf. Manag., vol. 28 , no. 1, pp. 107-130, 2015.

[21] W. W. Burke, Organization change: theory and practice. Sage Publications, 2017.

[22] N. Clohessy, T., Acton, T., and Rogers, "Blockchain Adoption: Technological, Organisational and Environmental Considerations," in Business Transformation through Blockchain, Volume 1, 1st ed., R. Treiblmaier, H. and Beck, Ed. Palgrave Macmillan, 2019, pp. 1-24.

[23] R. Houston, M., Acton, T., Clohessy, T., \& Godfrey, "Organisational factors that influence the Blockchain adoption in Ireland: A study by JE Cairnes School of Business \& Economics in association with the Blockchain Association of Ireland.," 2018.

[24] S. L. Jarvenpaa and B. Ives, "Executive involvement and participation in the management of information technology," MIS Q., vol. 15, no. 2, pp. 205-227, 1991.

[25] H. P. Borgman, B. Bahli, H. Heier, and F. Schewski, "Cloudrise: Exploring Cloud Computing Adoption and Governance with the TOE Framework," Proc. 46th Hawaii
Int. Conf. Syst. Sci. (HICSS '13), pp. 4425-4435, Jan. 2013.

[26] S. Fernandez and H. G. Rainey, "Managing succesful organizational change in the public sector," in Debating Public Administration, Routledge, 2017, pp. 7-26.

[27] K. Zhu, K. L. Kraemer, and J. Dedrick, "Information Technology Payoff in E-Business Environments: An International Perspective on Value Creation of E-Business in the Financial Services Industry," J. Manag. Inf. Syst., vol. 21, no. 1, pp. 17-54, Jan. 2004.

[28] A. S. Chwelos, P., Benbasat, I., \& Dexter, "Research report: empirical test of an EDI adoption model," Inf. Syst. Res., vol. 12, no. 3, pp. 304-321, 2001.

[29] D. Henderson, S. D. Sheetz, and B. S. Trinkle, "The determinants of inter-organizational and internal in-house adoption of XBRL: A structural equation model," Int. J. Account. Inf. Syst., vol. 13, pp. 109-140, 2012.

[30] Z. Huang, B. D. Janz, and M. N. Frolick, "A Comprehensive Examination of Internet-EDI Adoption," Inf. Syst. Manag., vol. 25, no. 3, pp. 273-286, Jul. 2008.

[31] P. Hart and C. Saunders, "Power and Trust: Critical Factors in the Adoption and Use of Electronic Data Interchange," Organ. Sci., vol. 8, no. 1, pp. 23-42, 1997.

[32] J. Yli-Huumo, D. Ko, S. Choi, S. Park, and K. Smolander, "Where Is Current Research on Blockchain Technology? - A Systematic Review," PLoS One, vol. 11, no. $10,2016$.

[33] M. Saunders, P. Lewis, and A. Thornhill, Research Methods for Business Students, 7e ed. Harlow, Essex, England: Pearson Education Limited, 2016.

[34] K. M. Eisenhardt and M. E. Graebner, "Theory Building from Cases: Opportunities and Challenges," Acad. Manag. J., vol. 50, no. 1, pp. 25-32, 2007.

[35] K. M. Eisenhardt, "Building theories from case study research," Acad. Manag. Rev., vol. 14, no. 4, pp. 432-550, 1989.

[36] L. Columbus, "Gartner Hype Cycle For Emerging Technologies, 2016 Adds Blockchain \& Machine Learning For First Time," 2016. .

[37] World Economic Forum, "Known Traveller Digital Identity," 2018.

[38] J. (WEF) Moavenzadeh and L. (Accenture) de Maar, "The Known Traveller: Unlocking the potential of digital identity for secure and seamless travel,” p. 44, 2018. 